\title{
Phased array compaction cell for measurement of the transversely isotropic elastic properties of compacting sediments
}

\author{
Kurt T. Nihei ${ }^{1}$, Seiji Nakagawa ${ }^{2}$, Frederic Reverdy ${ }^{3}$, Larry R. Myer ${ }^{2}$, Luca \\ Duranti $^{4}$, and Greg Ball ${ }^{4}$
}

\begin{abstract}
Sediments undergoing compaction exhibit transversely isotropic (TI) elastic properties that are described by five elastic constants. Continuous determination of all five constants in the laboratory during compaction is a difficult task. In this paper, we present a new experimental apparatus, the phased array compaction cell, for measuring the TI elastic properties of clay-rich sediments under uniaxial strain consolidation conditions. This apparatus uses matched sets of P- and S-wave ultrasonic transducers located along the sides of the sample and an ultrasonic P-wave phased array source together with a miniature P-wave receiver on the top and bottom ends of the sample. The phased array provides plane P-waves that are used to measure phase velocities over a range of angles. From these measurements, the five TI elastic constants can be recovered as the sediment is compacted, without the need for sample unloading, re-coring, or reorienting. Descriptions of the apparatus, data processing and an application demonstrating recovery of the evolving TI properties of a compacting marine sediment sample are provided in this paper.

${ }^{1}$ Formerly Lawrence Berkeley National Laboratory, California, U.S.A.; presently Chevron ETC, California, U.S.A. Email: knih@chevron.com.

${ }^{2}$ Lawrence Berkeley National Laboratory, California, U.S.A. Email: snakagawa@lbl.gov.

${ }^{3}$ Formerly Lawrence Berkeley National Laboratory, California, U.S.A.; presently CEA, Gif sur Yvette, France. Email: frederic.reverdy@cea.fr.

${ }^{4}$ Chevron ETC, California, U.S.A. Email: $\underline{\text { ludu@chevron.com; bagj@chevron.com. }}$
\end{abstract}

\section{INTRODUCTION}

Anisotropy in the overlying reservoir strata, when left uncorrected for, can detrimentally affect efforts to image reservoir structure and estimate reservoir properties using seismic methods. While clay-rich rocks often constitute the major fraction of sedimentary basins, only a 
limited number of experimental anisotropy studies have been performed on such rocks, especially for higher-porosity clay-rich sediments/rocks encountered in the first kilometer of depth. New data on the stress-dependent anisotropic properties of compacted clay-rich rocks provide valuable information that can be utilized to improve focusing in anisotropic imaging and for use in amplitude corrections for AVO. This information may also provide valuable insights on detecting overpressure in clay-rich sediments that can be used for borehole stability analysis.

The principal objective of this work is to characterize the elastic anisotropic properties of clay-rich sediments for consolidation conditions simulating compaction at depths of $0-2 \mathrm{~km}$. Ultrasonic transmission techniques are customarily used to measure the elastic properties of anisotropic materials. For transversely isotropic (TI) shales, the elastic stiffness coefficients can be determined from compressional and shear wave velocities measured along and across bedding, and a compressional wave velocity at an intermediate angle of incidence, typically $45^{\circ}$. In order to obtain these velocities on shale core under stress, the traditional characterization technique uses three cylindrical samples oriented parallel, perpendicular, and at an angle to the bedding (e.g., Hornby, 1998). Compressional and shear wave velocities are measured with transducers located on the ends of the sample. As Wang (2002a) points out, several drawbacks of this approach are the difficulty in coring the $45^{\circ}$ sample (shales are typically friable when cored at an angle to bedding), and the long testing times for multiple samples (pore pressure equilibration in low permeability shales have typical testing times of one week per sample).

Wang (2002a) developed a more efficient approach that requires only one sample cored along the bedding. This single-plug method recovers the five TI elastic constants of a cylindrical sample subjected to hydrostatic confinement using two sets of compressional wave transducers located on the sides and two shear and one compressional set of transducers located on the ends 
of the sample. Wang (2002b) used this method to measure the anisotropic properties of a suite of shales taken from sedimentary basins of interest for hydrocarbon production. More recent applications of the single-plug method by Dewhurst and Siggins (2006) and Sarout and Gueguen (2008) have improved the estimation of the $c_{13}$ elastic constant by correcting the off-symmetry axis qP wave measurement from group to phase velocity.

Although the single-plug and three-plug methods are well-suited for determining the TI elastic properties of competent rocks loaded hydrostatically, these methods are difficult to apply to softer, clay-rich sediments during compaction for several reasons. Firstly, non-hydrostatic stress states such as uniaxial strain compaction, are difficult to apply because the loading axis is non-coincident with the bedding plane normal vector. Secondly, clay-rich sediments can experience significant plastic deformation during compaction, requiring an unloading and recoring operation at each stress-level that the elastic properties are to be measured.

This paper describes a new laboratory device, the phased array compaction cell, for measuring the anisotropic properties of clay-rich rocks during consolidation. This device uses a set of compressional wave ultrasonic transducers and two sets of polarized shear wave ultrasonic transducers located on the sides of the sample, and a compressional wave ultrasonic phased array located on the bottom of the sample to recover the five TI elastic stiffness coefficients. The novel feature of this apparatus is the use of the phased array to measure the phase velocity of quasicompressional (qP) waves over a range of angles relative to bedding. These multiple off-axis phase velocity measurements provide redundancy in the estimation of $c_{13}$. Additionally, because the sample is loaded orthogonal to bedding in a stiff, thick-walled vessel, the sample can be considered to be subjected to uniaxial strain (one dimensional) consolidation, the state-of-stress that is commonly assumed to approximate conditions in situ (Stoll, 2006). 
In the following, we first describe the design parameters of the phased-array compaction cell. Next, we explain how the five VTI (TI with a vertical axis of symmetry) elastic constants are determined from the measured waves. A benchmark application using Phenolite, a manufactured anisotropic material, is given to demonstrate and validate the apparatus and the testing and data processing methodologies. Finally, an application of this device to measure the evolution of compaction-induced VTI anisotropy in a clay-rich sediment is presented.

\section{PHASED ARRAY COMPACTION CELL}

\section{Apparatus design considerations}

The general consideration that went into the design of the apparatus was that it be capable of measuring the transversely isotropic (TI) elastic constants on samples prepared from standard 3inch diameter geochemical and geotechnical cores, while undergoing uniaxial strain compaction with controlled pore pressure. The underlying assumption made here is that a sediment sample subjected to one-dimensional compaction will develop VTI elastic properties with an axis of symmetry that is coincident with the loading axis. A schematic illustration and photographs of the phased array compaction cell are shown in Figs. 1 and 2. The cell is a thick-walled stainless steel vessel with a slot-shaped boring $5.0 \mathrm{~cm}$ long by $1.5 \mathrm{~cm}$ across by $5.0 \mathrm{~cm}$ in depth. The slotshaped sample geometry accommodates the rectangular footprint of a 32 element P-wave phased array $(47.9 \mathrm{~mm} \times 15.0 \mathrm{~mm})$. The shorter dimension across the slot also allows measurement of strongly attenuating, short-wavelength ultrasonic shear waves that result from the low shear wave velocities in unconsolidated clay-rich sediments $\left(V_{S}<500 \mathrm{~m} / \mathrm{s}\right.$; Leurer, 2004; Buckingham, 2005). Compaction of relatively compliant clay-rich sediments and unconsolidated sands is approximately one-dimensional (i.e., uniaxial strain) because of the small lateral deformation 
provided by the thick $(>1.5 \mathrm{~cm})$ stainless steel walls of the cell. Although the slot geometry can result in friction between the sample and the cell wall, this effect can be reduced by using a short sample. Additionally, for soft sediments that exhibit large plastic and viscoelastic deformation, the effect of friction on the development of anisotropy is typically small.

Descriptions of the three sets of ultrasonic transducers for measuring P, SV, and SH wave velocities along the bedding direction, the $\mathrm{P}$-wave phased array for measuring $\mathrm{qP}$ wave phase velocities from $0^{\circ}$ out to $\sim 45^{\circ}$, and the methodology for extracting the five VTI elastic constants from these measurements are given in the following sections.

\section{Ultrasonic transducers}

Three sets of ultrasonic tranducers are employed to measure $\mathrm{P}\left(90^{\circ}\right), \mathrm{SV}\left(90^{\circ}\right)$, and $\mathrm{SH}\left(90^{\circ}\right)$ waves propagating along the bedding direction (i.e., $90^{\circ}$ relative to $x_{3}$, the axis of symmetry). These ultrasonic transducers were constructed with broadband, damped, $1 \mathrm{MHz}$ resonant, piezoceramic disks potted in a stiff epoxy resin, and are capable of withstanding pressures up to 10 MPa (Valpey-Fisher Corp.). The transducers are located in cylindrical holes along the walls of the slot-shaped bore. O-ring seals are used to seal the gap between the transducers and the confining cell near their point of entry into the slot-shaped bore (Fig. 1b). A removable retaining clamp secures the tranducers in place, and allows transducers to be removed for cleaning and replacement. P-waves are generated using a square wave pulser (IRCO M1k-20 pulser) with a 1 $\mu$ s width and $130 \mathrm{~V}$ peak-peak amplitude.

For S-wave generation, the low shear wave velocities in clay-rich sediments result in short wavelength $1 \mathrm{MHz}$ signals that suffer strong geometrical spreading and intrinsic attenuation amplitude loss. To enable penetration through the clay-rich sample, S-waves are generated by 
driving the transducers below the $1 \mathrm{MHz}$ resonance frequency with a broadband (Ricker) wavelet. Experimentation has revealed that good quality waveforms in the $30-100 \mathrm{kHz}$ range can be obtained from the sub-resonance driven S-wave transducers, with the output waveform mirroring the input, and with minimal coda before and after the S-wave arrival. The electronics to drive these transducers consists of an arbitrary function generator (SRS DS345 Synthesized Function Generator) to generate the wavelet, and a wideband amplifier (Krohn-Hite 7602M) to amplify the wavelet to $130 \mathrm{~V}$ peak-peak.

\section{Phased array}

A 32-element P-wave phased array is used to generate plane waves over a range of angles from $0^{\circ}$ out to $\sim 45^{\circ}$. The principal purpose of using the phased array is to enable measurements of the off-symmetry axis P-wave phase slownesses in the $x_{1}-x_{3}$ plane (Fig. 1). Phase slownesses (as opposed to group slownessnes) are single-valued functions of the angle of incidence. This allows unambiguous identification of the P-wave when the anisotropic properties lead to wave triplication (i.e., multi-pathing). Additionally, a simple algebraic expression can be derived from the Christoffel equation for estimating the elastic constant $c_{13}$ from the measured phase P-wave slownesses.

The 32-element P-wave phased array was manufactured by Materials Systems Incorporated (http://www.matsysinc.com/). The array was fabricated from a 1-3 piezocomposite (MSI-53 ceramic with 13-32 ultra-hard matrix) with a rigid, high-impedance matching layer on the face of the array and a rigid absorbing backing. The 1-3 piezocomposite is a recent innovation in the piezoelectric materials consisting of an array of piezoceramic rods embedded in a polymer

matrix. Relative to standard phased arrays fabricated from piezoceramic plates, 1-3 
piezocomposite arrays have a higher piezoelectric coupling coefficient, larger thickness expansion efficiency, and improved one-dimensional directivity. In the face of the array, each of the 32 elements has dimensions $15 \mathrm{~mm} \times 1.4 \mathrm{~mm}$, with a $0.1 \mathrm{~mm}$ separation between the elements. The array was potted into the compaction vessel with a hard epoxy.

The phased array can be used as either as a source or a detector. In the experiments described in this paper, the array is used as a source by firing each of the 32 piezoceramic elements separately with a $1 \mu$ s width, $130 \mathrm{~V}$ peak-peak square wave (IRCO Mlk-20 pulser), and recording the transmitted waves with a piezoelectric detector located at the center of the loading piston. For this set-up, each element produced Ricker-like broad-band wavelets with a central frequency of approximately $1 \mathrm{MHz}$. The detector is a broadband P-wave "pinducer" (pin-shaped transducer) with a $1.3 \mathrm{~mm}$ diameter piezoceramic disk (Valpey-Fisher VP-1093). To speed-up acquisition time, a multiplexer (Keithley 7002 switch system) was used to automate the switching of the amplified source wavelet from the pulser/amplifier to the 32 elements of the phased array. The resulting data set from the phased array is effectively a 32 trace commonreceiver gather. The procedure for synthetic phasing of this common-receiver data to form plane waves over a range of incidence angles is described in the next section.

\section{DETERMINATION OF VTI ELASTIC PARAMETERS}

\section{Recovery of $c_{11}, c_{33}, c_{55}, c_{66}$}

Three of the five elastic constants for the VTI sample can be obtained directly from transmission measurements of $\mathrm{P}$ - and S-waves made with the ultrasonic transducers located on the sides of the sample (i.e., propagation along the bedding direction; Fig. 1), 


$$
\begin{aligned}
& C_{11}=C_{22}=\rho V_{P 90^{\circ}}^{2} \\
& C_{44}=C_{55}=\rho V_{S V 90^{\circ}}^{2} \\
& C_{66}=\rho V_{S H 90^{\circ}}^{2}
\end{aligned}
$$

where $\rho$ is the density, and $V_{P 90^{\circ}}, V_{S V 90^{\circ}}, V_{S H 90^{\circ}}$ are the P- and S-wave (vertical and horizontally polarized) velocities. The fourth elastic constant $c_{33}$ can be recovered directly from the zerooffset transmission measurement between the center element of the phased array and the pinducer receiver located in the center of the loading piston (i.e., propagation perpendicular to bedding; Fig. 1a),

$$
c_{33}=\rho V_{P 0^{\circ}}^{2} .
$$

Because these waves travel either along the symmetry plane $\left(x_{3}=0\right)$ or along the symmetry axis $\left(x_{3}\right)$, their particle motions are pure compressional and shear, and there is no ambiguity between phase and group velocity (i.e., $V_{\text {phase }}=V_{\text {group }}$ ).

\section{Recovery of $c_{13}$}

The fifth elastic constant $c_{13}$ is important for seismic imaging in VTI media as it controls the shape of the P-wave normal moveout at near-to-mid source-receiver offsets (Thomsen, 1986). Here, we recover $c_{13}$ from the phased array transmission measurements through synthetic phasing of the common-receiver data generated by the $N=32$ element source array to form the plane wave transmission data (Reverdy et al., 2000). This synthesis of the plane wave response is accomplished by time shifting and summing the traces in the common-receiver gather, 


$$
u(t)=\sum_{i=1}^{N} u_{s_{i}}\left[t+\left(i-\frac{N+1}{2}\right) \delta t\right]
$$

Note that he center of the array is located between the elements 16 and 17. This process of plane wave synthesis is displayed graphically in Fig. 3. For this geometry, the plane wave propagating at an angle $\theta$ has a horizontal slowness $p_{1}$ that is prescribed by the source time shift $\delta$, and the source element spacing $\delta x$ :

$$
p_{1}=\frac{\delta t}{\delta x}
$$

The vertical slowness $p_{3}$ is determined by the travel time $\tau$ of the synthesized plane wave and the vertical propagation distance $L$,

$$
p_{3}=\frac{\tau}{L}
$$

The angle of plane wave propagation $\theta$ can be computed from the slowness components,

$$
\theta=\tan ^{-1}\left(\frac{p_{1}}{p_{3}}\right)
$$

This process of plane wave synthesis is equivalent to slant-stack ( $\tau$ - $p$ ) processing via a Radon transform (e.g., Kebaili and Schmitt, 1997; Mah and Schmitt, 2001, 2003; van der Baan and Kendall, 2002). In slant-stack processing, the plane wave response is synthesized from the common-receiver $x$ - $t$ data by summing the traces along a line starting at time $\tau$ on the zero offset trace, with a slope $p_{1}=d t / d x$, which is the horizontal slowness. The vertical slowness is computed from the travel time at zero offset and the thickness of the sample as in Eq. 7. 
This processing yields the $q P$ (quasi-P) slownesses $\left(p_{1}, p_{3}\right)$ over a range of angles, typically 0 to $\sim 45^{\circ}$, that partially map-out the shape of the qP slowness surface. Miller and Spencer (1994) demonstrated that the Christoffel equations for a VTI medium that describe qP and qSV plane wave propagation can be formulated as a linear inverse problem of estimating $c_{13}$ from $\mathrm{qP}$ slowness measurements provided that $c_{55}$ is known. The Miller-Spencer inversion scheme for $c_{13}$ involves solution of the following linear system:

$$
a_{11} \mathbf{U}+a_{33} \mathbf{V}+a \mathbf{W}=\mathbf{D},
$$

where the components of the vectors $\mathbf{U}, \mathbf{V}, \mathbf{W}, \mathbf{D}$ and the coefficients are given by

$$
\begin{aligned}
& U_{i}=a_{55} X_{i}^{2}-X_{i} \\
& V_{i}=a_{55} Z_{i}^{2}-Z_{i} \\
& W_{i}=X_{i} Z_{i} \\
& D_{i}=a_{55}\left(X_{i}+Z_{i}\right)-1 \\
& a=a_{11} a_{33}+a_{55}^{2}-\left(a_{13}+a_{55}\right)^{2}, \\
& a_{I J}=c_{I J} / \rho \\
& a_{13}=\left(a_{11} a_{33}+a_{55}^{2}-a\right)^{1 / 2}-a_{55}
\end{aligned}
$$

where $i=1,2, \ldots, N_{\theta}(\geq 3)$ and the data vectors are defined as

$$
\begin{aligned}
& X_{i}=p_{1}^{2}\left(\theta_{i}\right) \\
& Z_{i}=p_{3}^{2}\left(\theta_{i}\right)
\end{aligned} .
$$

The multiple qP slowness measurements $\left(p_{1}, p_{3}\right)$ in Eq. 11 together with Eq. (9) form an overdetermined system of equations that can be solved for $c_{13}$ via least squares inversion. Note that in this inversion process, the input $c_{55}$ remains fixed, but the input $c_{11}$ and $c_{33}$ (i.e., the endpoints of the $\mathrm{qP}$ slowness surface) are adjusted as the $\mathrm{qP}$ slowness surface is fit to the slowness data in a least squares sense. Compared to the estimates of the four other TI elastic constants, robust estimation of $c_{13}$ requires considerably more effort, and has a larger 
uncertainty than the other four $c_{I J}$ 's. A graphical illustration of the qP, qSV, and qSH slowness surfaces with the ultrasonic transmission measurements and their relationships to the five VTI elastic constants is shown in Fig. 4.

\section{SYSTEM VALIDATION ON PHENOLITE}

To verify the accuracy of the phased array hardware and methodology for recovering $c_{13}$ from the plane P-waves traveling at an angle to the VTI axis of symmetry, a validation test was carried out on a rectangular block of Phenolite, a laminated material composed of thin sheets impregnated with a synthetic resin. The particular variety of Phenolite used in this test was composed of woven sheets. The dimensions and density of the Phenolite sample were $15.08 \mathrm{~mm}$ $\times 15.62 \mathrm{~mm} \times 51.00 \mathrm{~mm}$ and $1357 \mathrm{~kg} / \mathrm{m}^{3}$, respectively. The two sides of the Phenolite sample orientated parallel to the layering direction of the woven fabric were machined flat and parallel in preparation for placement of the 32-element phased array source and the pinducer receiver. In this configuration, the normal incidence propagation is along the $x_{3}$ axis, and the $x_{1}$ and $x_{2}$ axes lie on the plane of the fabric sheets. The presence of the weave in the fabric produces a laminated material that is properly described as an orthotropic material.

Three elastic constant $c_{11}, c_{55}$, and $c_{66}$, are determined by direct measurement along the $x_{1}$ direction by making use of the pairs of transducers on the side of the compaction cell (Fig. 1b; Eqs. (1) - (3) ). The two remaining elastic constants $c_{33}$ and $c_{13}$ are recovered from the phased array measurements in the $x_{2}-x_{3}$ plane (Fig. 1a) using the plane wave synthesis and linear inversion methodology described in Eqs. (5) - (11). For the Phenolite sample, the phased array measurements, the synthesized plane waves, and the recovered slowness surfaces are displayed in Fig. 5. 
The five elastic constants obtained for the Phenolite sample are shown in Table 1, along with independent measurements made on Phenolite cut from the same stock material into two hexagonal blocks oriented in the $x_{1}-x_{3}$ and $x_{2}-x_{3}$ planes. Overall, there is good agreement between these independent sets of measurements, with the small deviations being attributed to the orthotropic nature of Phenolite and the TI assumption implicit in the phased array elastic constant determination methodology.

Also included in Table 1 are several published values for the elastic constants of Phenolite. It should be noted that Phenolite is a generic name for a broad class of laminated materials composed of thin sheets of material (e.g., paper, fiberglass) embedded in a synthetic resin, and that the Phenolite used in these measurements have different densities than the Phenolite used in our tests. Nevertheless, the agreement between the elastic constants obtained from the phased array measurements and these published values are good.

\section{ANISOTROPIC PROPERTIES OF A COMPACTING MARINE SEDIMENT}

To evaluate the utility of the phased array compaction cell for measuring the evolution of anisotropy in compacting sediments, a clay-rich sediment sample was obtained from a shallow geotechnical boring (76.4 m below mud line) in the Typhoon Field, located in the Green Canyon area of the Gulf of Mexico (water depth $\sim 610 \mathrm{~m}$ ). The composition of the clay-rich sediment obtained from QXRD in \% weight is: 65\% clay (10\% kaolinite + 55\% 2:1 clay+mica), $25 \%$ quartz, $4 \%$ feldspar, $4 \%$ plagioclase, $1 \%$ dolomite, and $1 \%$ calcite $\&$ pyrite.

Because the integrity of the sample was that of a stiff clay, the slot-shaped sample required for the phased array compaction cell (Fig. 1b) was cut from the core using a slot-shaped cutter attached to a mechanical press. A set of mini cores were also cut from the core for density, 
porosity, elemental composition analysis, and texture analysis. Following placement of the slotshaped sample in the compaction cell, a thin sheet of filter paper was placed between the sample and the loading piston to allow uniform drainage of the pore fluid during compaction. The compaction cell was placed in a load frame, and axial load was applied with a hydraulic cylinder (Enerpac C-101) controlled by a syringe pump (ISCO 260D). The pore fluid pressure was maintained at atmospheric pressure throughout the test, and the expelled pore fluid was measured by a $0.1 \mathrm{~mL}$ graduated burette. Axial displacement was measured with a precision indicator (Starrett 2700). The protocol followed during this test consisted of a series of $0.5 \mathrm{MPa}$ steps in axial stress from $0 \mathrm{MPa}$ to $6 \mathrm{MPa}$. Assuming an average overburden stress gradient of $1 \mathrm{psi} / \mathrm{ft}$, this stress range is equivalent to a depth of approximately $870 \mathrm{~m}$.

The measured density and porosity during uniaxial strain (i.e., one-dimensional) compaction is displayed in Fig. 6. Data points with filled circles denote density and porosity measurements made on the sample prior to compaction (1.73 MPa is the estimated in situ axial stress) and postcompaction (5.97 MPa), while the open circles denote density and porosity values inferred from the measured length change and expelled pore fluid during the compaction of the sample. These density and porosity data are in good agreement with the clay-rich sediment measurements reported by Leurer (2004).

The raw $\mathrm{P}$ - and S-wave traces recorded during the compaction experiment are displayed in Fig. 7 and Fig. 8, and the corresponding velocities in Fig. 9. In general, the P-wave data is noisefree and impulsive, allowing accurate travel-time estimates to be obtained. The SV- and SHwave data, in contrast, have less impulsive first breaks and suffer from the presence of coherent noise that may include precursory waves reflected and refracted from the cell walls, loading piston and the phased array. Significant differences in the SV- and SH-wave data also can be 
observed between the face-to-face reference pulse and the traces for the various stress levels, indicating that the pulse is experiencing significant dispersion during propagation through the sample. This dispersion affects the accuracy of the SV- and SH-wave travel time estimates obtained from cross-correlation of the reference pulse with the traces for the different stress levels, particularly at the lower stress levels where the dispersion is largest. These complexities serve to reduce the accuracies of the shear wave slowness estimates, and, hence, the estimates of $c_{55}$ and $c_{66}$. It should be noted that significant improvement in the travel time estimation can be obtained by band-passing the reference pulse to match the spectrum of the measured trace prior to cross-correlation. This operation, which effectively compensates for the significant dispersion that the shear waves experience at the lower stress levels, has subsequently been adopted in our more recent tests. Finally, an additional problem that was encountered during this experiment was the intermittent failure of the SH transducer that resulted from a short circuit (missing SHwave velocity data for 4 loads: 4.0, 4.5, 5.5, $6.0 \mathrm{MPa}$ ), and that was subsequently corrected by improving the mechanical integrity of the SH-wave transducer following this test.

Slowness surfaces for three axial stresses are shown in Fig. 10. The qP slownesses were obtained via synthetic phasing of the common-receiver array data, as described in Eq. (5) - (8). The slowness data was converted to elastic constants using Eqs. (1) - (4) and (9) - (11). The resulting stress-dependent, VTI elastic constants and corresponding Thomsen's (1986) and anellipticity (Tsvankin, 2001) parameters, 


$$
\begin{aligned}
& \varepsilon=\frac{c_{11}-c_{33}}{2 c_{33}} \\
& \gamma=\frac{c_{66}-c_{55}}{2 c_{55}} \\
& \delta=\frac{\left(c_{13}+c_{55}\right)^{2}-\left(c_{33}-c_{55}\right)^{2}}{2 c_{33}\left(c_{33}-c_{55}\right)}, \\
& \eta=\frac{\varepsilon-\delta}{1+2 \delta}
\end{aligned}
$$

are displayed in Fig. 11. While the elastic constants appear as monotonic functions of axial stress, the Thomsen's parameters show considerably more scatter. An analysis of the errors in the velocities, elastic constants and Thomsen's parameters is provided in Appendix A, along with estimates of these errors in Table 2. This analysis demonstrates that the elastic constants will have larger errors than the corresponding velocities, and that the Thomsen's parameters can have very large errors when the anisotropy is weak, as in the case of the compacting clay-rich sample used here.

The change in texture resulting from one dimensional consolidation of the clay-rich sample is evident in the pre- and post-compaction SEM photomicrographs of Fig. 12 taken along vertical slices through the samples. The photomicrographs show the collapse of the pores and the associated loss of the pore fluid (brine: $\mathrm{O}, \mathrm{Na}, \mathrm{Cl}$ ). X-ray diffraction pole figures obtained from oriented mini-cores taken from pre- and post-compaction samples are shown in Fig. 13. These pole figures represent the average crystallographic orientation of many mineral grains over a sample area of $\sim 1 \mathrm{~mm}^{2}$, and are measured with X-ray texture goniometry (Aplin et al., 2003; Wenk et al., 2007; Lonardelli et al., 2007; Voltolini et al., 2009). The increase in the maximum pole density with compaction is consistent with an improved alignment of the clay platelets that results from mechanical compaction (Ruud et al., 2003; Johansen et al., 2004). While an 
analysis of evolution of texture in clay-rich sediments and the corresponding generation of seismic anisotropy lies outside of the scope of this paper, the apparatus described here is ideallysuited for investigating the evolution of texture and seismic anisotropy in flocculated clay aggregates as they are subjected to burial (Baker et al., 1993; Sintubin, 1994).

\section{DISCUSSION}

At early stages of diagenesis, clay-rich sediments can develop elastic anisotropy because of compaction and alignment of clay platelets. Understanding the evolution of this mechanically induced anisotropy as a function of burial depth (or increases in effective stress) is important for proper seismic imaging in sedimentary basins. The phased-array compaction cell described in this paper is a new laboratory tool that can fully characterize the evolution of transverse isotropy in soft sediments using a single sample. This apparatus utilizes conventional ultrasonic transducers to determine $c_{11}, c_{55}$, and $c_{66}$, and an ultrasonic phased array to determine $c_{13}$ and $c_{33}$. We demonstrated the capability of the apparatus for characterizing the evolution of anisotropy using a clay-rich marine sediment from the Gulf of Mexico.

The phased array compaction cell can also be applied to examine the evolution of stressinduced anisotropy in weakly-consolidated sands. Sherlock et al. (2007) used the apparatus on a dry quartz sand pack. Note that, unlike highly-plastic, water-saturated clay-rich sediments, compaction of dry sands may result in large friction between the cell wall and the sample, which may result in an underestimation of anisotropy for a given compaction stress. For such samples, the sample height-to-width ratio should be kept small to minimize the effects of wall friction.

In most applications, the apparatus will measure $\mathrm{qP}$ and $\mathrm{S}$ waves in different frequency bands. Unfortunately, this is unavoidable because of the small sample size and the very large 
differences in the $\mathrm{qP}$ and $\mathrm{S}$ wave velocities. Therefore, in determining the TI elastic constants, the frequency-dependency of elastic constants is assumed to be small. This should be a valid approximation for dry and fully saturated samples, including both clay-rich sediments and sands. However, if a sediment sample is partially-saturated, the resulting velocity dispersion may be non-negligible.

Finally, it should be noted that the recovery of $c_{13}$ might benefit from the use of a shear wave phased array because of the higher sensitivity of the qSV wave to $c_{13}$. This can be seen through the following simple sensitivity analysis,

$$
\frac{\partial V_{q M}}{\partial c_{13}}=\frac{\partial V_{q M}}{\partial \delta} \cdot \frac{\partial \delta}{\partial c_{13}},
$$

where Thomsen's weak anisotropy expressions (Thomsen, 1986) are used for the qP and qSV phase velocities,

$$
\begin{aligned}
& M=P, S V \\
& V_{q P} \approx V_{P 0^{\circ}}\left(1+\delta \sin ^{2} \theta \cos ^{2} \theta+\varepsilon \sin ^{4} \theta\right) \\
& V_{q S V} \approx V_{S V 0^{\circ}}\left[1+\frac{V_{P 0^{\circ}}^{2}}{V_{S V 0^{\circ}}^{2}}(\varepsilon-\delta) \sin ^{2} \theta \cos ^{2} \theta\right] . \\
& \delta=\frac{\left(c_{13}+c_{55}\right)^{2}-\left(c_{33}-c_{55}\right)^{2}}{2 c_{33}\left(c_{33}-c_{55}\right)}
\end{aligned}
$$

Substituting the expressions in Eq. (14) in Eq. (13) yields the following ratio of the sensitivity of the $\mathrm{qSV}$ and $\mathrm{qP}$ wave velocities to $c_{13}$,

$$
R=\frac{\left|\frac{\partial V_{q S V}}{\partial c_{13}}\right|}{\left|\frac{\partial V_{q P}}{\partial c_{13}}\right|}=\frac{V_{P 0^{\circ}}}{V_{S V 0^{\circ}}}
$$


For weakly consolidated rocks, the ratio in Eq. (15) can be in the $2-5$ range, indicating that qSV wave velocities will be 2 to 5 times more sensitive to $c_{13}$ than $\mathrm{qP}$ wave velocities. It should be noted, however, that qSV wave velocities in weakly consolidated sediments can be very difficult to measure because these velocities are typically small. The low velocities result in short wavelengths that experience large geometrical spreading and intrinsic attenuation losses. Longer qSV wavelengths can be obtained through the use of lower frequencies, but the practical difficulties of fabricating a lower frequency shear wave array should be considered. Currently, the commercial availability of broadband shear wave phased arrays is very limited. However, if small and compact shear wave phased arrays become available in the future, the robustness of the phased array compaction cell for determining $c_{13}$ could potentially be improved.

\section{CONCLUSIONS}

A new experimental apparatus for measuring the transverse isotropic properties of soft sediments during uniaxial strain (one-dimensional) consolidation has been developed. The phased array compaction cell utilizes conventional ultrasonic transducers to determine $c_{11}, c_{55}$ and $c_{66}$, and offaxis qP plane wave slowness measurements using an ultrasonic phased array to provide $c_{13}$ and $c_{33}$. The utility of the apparatus for characterizing the evolution of anisotropy was demonstrated with a clay-rich marine sediment from the Gulf of Mexico.

Current testing is underway to apply the phased array compaction cell to shallow marine sediments from hydrocarbon-bearing basins to more-fully characterize the evolution of anisotropy from the seafloor to deeper shales, and the relation of this anisotropy to clay and silt content and stress. Additionally, tests on unconsolidated sands demonstrate that the apparatus 
can be used to measure stress-induced anisotropy in poorly consolidated clastics (Sherlock et al., 2007).

\section{ACKNOWLEDGMENTS}

We gratefully acknowledge Don Sherlock, Russ Ewy, Rudy Wenk, Keith Katahara, Colin Sayers and Michael Schoenberg for sharing their insights and expertise on clay-related anisotropy, Doug McCarty for performing the EDAX and SEM, and Andrew Aplin for providing the X-ray goniometry measurements. We thank Chevron Deepwater Producing Operations for providing the Typhoon geotechnical core. We also thank the reviewers for improving the content and readability of this paper. This work was supported by the Assistant Secretary of Fossil Energy, U.S. Department of Energy under Contract No. DE-AC02-05CH11231, and by the Chevron Energy Technology Company. 


\section{APPENDIX A}

\section{UNCERTAINTIES}

The uncertainties in the velocities, elastic constants, and Thomsen's parameters are considered here using standard analysis for errors propagating through functional relationships (e.g., Taylor, 1982). In this analysis, the errors stemming from the measured travel times cascade through to the computed velocities, VTI elastic constants and Thomsen's parameters, under a simplifying assumption that the variables are uncorrelated.

For the computed velocities, the absolute velocity error $\Delta V$ is computed from the estimated travel time and sample length errors $\Delta T$ and $\Delta L$,

$$
\Delta V=\left[\left(\frac{\partial V}{\partial T}\right)^{2} \Delta T^{2}+\left(\frac{\partial V}{\partial L}\right)^{2} \Delta L^{2}\right]^{1 / 2}
$$

In Eq. (A-1), the length measurement error contribution is negligible ( $\Delta L \approx \pm 10 \mu \mathrm{m})$. Dropping the second term and using $V=L / T$, the normalized velocity error simplifies to

$$
\frac{\Delta V}{V} \approx \frac{\Delta T}{T}
$$

Eq. (A-2) can be used to estimate the normalized velocity errors for the P (0 deg.), P (90 deg.), SV (90 deg.) and SH (90 deg.) measurements given estimates of the travel time errors.

The error in the VTI elastic constant $c_{11}$ can be computed from the estimated velocity error as follows

$$
\Delta c_{11}=\left[\left(\frac{\partial c_{11}}{\partial V_{P 90^{\circ}}}\right)^{2} \Delta V_{P 90^{\circ}}^{2}\right]^{1 / 2},
$$


where $c_{11}=\rho V_{P 90^{\circ}}^{2}$. The normalized error is then

$$
\frac{\Delta c_{11}}{C_{11}}=\frac{2 \Delta V_{P 90^{\circ}}}{V_{P 90^{\circ}}} .
$$

Note that similar expressions to Eq. (A-4) hold for $c_{33}, c_{55}$ and $c_{66}$,

$$
\begin{aligned}
& \frac{\Delta c_{33}}{C_{33}}=\frac{2 \Delta V_{P 0^{\circ}}}{V_{P 0^{\circ}}}, \\
& \frac{\Delta c_{55}}{C_{55}}=\frac{2 \Delta V_{S V 90^{\circ}}}{V_{S V 90^{\circ}}}, \\
& \frac{\Delta c_{66}}{C_{66}}=\frac{2 \Delta V_{S H 90^{\circ}}}{V_{S H 90^{\circ}}} .
\end{aligned}
$$

An estimate of the error in $c_{13}$ is a bit more involved as this elastic constant is determined via least squares inversion of Eq. (9). The formal approach would be to use a mapping of the (measured) slowness errors into the model-fitting errors of the least squares framework (e.g., Aster et al., 2005). At present, we have not implemented this analysis into our solution of Eq. (9), but this is a straightforward and worthwhile endeavor that will be implemented in the future.

The errors for the Thomsen's parameters (Eq. (12)) can be obtained using the same methodology of Eq. (A-1). The normalized errors for $\varepsilon, \gamma$ and $\delta$ are as follows,

$$
\begin{aligned}
& \frac{\Delta \varepsilon}{\varepsilon}=\frac{c_{11}}{2 c_{33} \varepsilon}\left[\left(\frac{\Delta c_{11}}{c_{11}}\right)^{2}+\left(\frac{\Delta c_{33}}{c_{33}}\right)^{2}\right]^{1 / 2}, \\
& \frac{\Delta \gamma}{\gamma}=\frac{c_{66}}{2 c_{55} \gamma}\left[\left(\frac{\Delta c_{66}}{c_{66}}\right)^{2}+\left(\frac{\Delta c_{55}}{c_{55}}\right)^{2}\right]^{1 / 2},
\end{aligned}
$$




$$
\frac{\Delta \delta}{\delta} \approx \frac{c_{13}}{2 c_{33} \delta}\left[\left(\frac{\Delta c_{13}}{c_{13}}\right)^{2}+\left(\frac{\Delta c_{33}}{c_{33}}\right)^{2}\right]^{1 / 2} .
$$

Eq. (A-10) was obtained using the "acoustic" qP approximation of Alkhalifah (1998), where it was demonstrated that $c_{55}$ has a negligibly effect on the velocity of the qP wave and can be set to zero.

Some conclusions that can be drawn from this highly simplified error analysis are: (1) the normalized errors for $c_{11}, c_{33}, c_{55}$ and $c_{66}$ in Eqs. (A-4) - (A-7) are twice the corresponding velocity errors, and (2) the normalized errors for $\varepsilon, \gamma$ and $\delta$ in Eqs. (A-8) - (A-10) will become magnified when the anisotropy is weak, i.e., when $\varepsilon, \gamma$ and $\delta$ are small. Estimates of these errors are given in Table 2. 


\section{REFERENCES}

Alkhalifah, T., 1998, Acoustic approximations for processing in transversely isotropic media: Geophysics, 63, 623-631.

Aplin, A. C., Matenaar, I. F., and van der Pluijm, B., 2003, Influence of mechanical compaction and chemical diagenesis on the microfabric and fluid flow properties of Gulf of Mexico mudstones: J. Geochem. Expl., 78-79, 449-451.

Aster, R. C., Borchers, B., and Thurber, C. H., 2005, Parameter estimation and inverse problems: Elsevier Academic Press.

Baker, D. W., Chawla, K. S., and Krizek, R. J., 1993, Compaction fabrics of pelites: experimental consolidation of kaolinite and implications for analysis of strain in slate: $\mathrm{J}$. Struct. Geol., 15, 1123-1137.

Buckingham, M. J., 2005, Compressional and shear wave properties of marine sediments: Comparisons between theory and data: J. Acoust. Soc. Am., 117, 137-152.

Cheadle, S. P., Brown, R. J., and Lawton, D. C., 1991, Orthorhombic anisotropy: A physical seismic modeling study: Geophysics, 56, 1603-1613.

Dewhurst, D. N. and Siggins, A. F., 2006, Impact of fabric, microcracks and stress field on shale anisotropy: Geophys. J. Int., 165, 135-148.

Hornby, B., 1998, Experimental laboratory determination of the dynamic elastic properties of wet, drained shales: J. Geophys. Res., 103(B12), 29945-29964.

Johansen, T. A., Ruud, B. O., and Jakobsen, M., 2004, Effect of grain scale alignment on seismic anisotropy and reflectivity of shales: Geophysical Prospecting, 52, 133-149.

Kebaili, A. and Schmitt, D. R., 1997, Ultrasonic anisotropic phase velocity determination with the Radon transform: J. Acoust. Soc. Am., 101, 3278-3286. 
Leurer, K. C., 2004, Compressional- and shear-wave velocities and attenuation in deep-sea sediment during laboratory compaction: J. Acoust. Soc. Am., 116, 2023-2030.

Lonardelli, I., Wenk, H.-R., and Ren, Y., 2007, Preferred orientation and anisotropy in shales: Geophysics, 72, D33-D40.

Mah, M., and Schmitt, D. R., 2001, Experimental determination of the elastic coefficients of an orthorhombic material: Geophysics, 66, 1217-1225.

Mah, M., and Schmitt, D. R., 2003, Determination of the complete elastic stiffnesses from ultrasonic phase velocity measurements: J. Geophys. Res., 108(B1), 2016, doi:10.1029/2001JB001586.

Miller, D. E., and Spencer, C., 1994, An exact inversion for anisotropic moduli from phase slowness data: J. Geophys. Res., 99(B11), 21,651-21,657.

Reverdy, F. and Audoin, B., 2000, Elastic constants determination of anisotropic materials from phase velocities of acoustic waves generated and detected by lasers: J. Acoust. Soc. Am., 109, 1965-1972.

Ruud, B. O., Jakobsen, M., and Johansen, T. A., 2003, Seismic properties of shales during compaction: SEG Expanded Abstracts, 22, 1294-1297, doi:10.1190/1.1817522.

Sarout, J. and Gueguen, Y., 2008, Anisotropy of elastic wave velocities in deformed shales: Part 1—Experimental results: Geophysics, 73, D75-D89.

Sherlock, D., Nihei, K., Nakagawa, S., and Duranti, L., 2007, Stress-induced velocity anisotropy measurements in unconsolidated sand using a phased-array uniaxial compaction cell: SEG Expanded Abstracts, 26, 1550-1554, doi:10.1190/1.2792791. 
Sintubin, M., 1994, Clay fabrics in relation to the burial history of shales: Sedimentology, 41, 1161-1169.

Stoll, R. D., 2006, Sediment acoustics: Peninsula Publishing.

Taylor, J. R., 1982, An introduction to error analysis: The study of uncertainties in physical measurements: University Science Books.

Thomsen, L., 1986, Weak elastic anisotropy: Geophysics, 51, 1954-1966.

Tsvankin, I., 2001, Seismic signatures and analysis of reflection data in anisotropic media: Elsevier Science Ltd.

van der Baan, M. and Kendall, J. M., 2002, Estimating anisotropy parameters and traveltimes in the $\tau$-p domain: Geophysics, 67, 1076-1086.

Voltolini, M., Wenk, H.-R., Mondol, N. H., Bjørlykke, K., and Jahren, J., 2009, Anisotropy of experimentally compressed kaolinite-illite-quartz mixtures: Geophysics, 74, D13-D23.

Wang, Z., 2002a, Seismic anisotropy in sedimentary rocks, part 1: A single-plug method: Geophysics, 67, 1415-1422.

Wang, Z., 2002b, Seismic anisotropy in sedimentary rocks, part 2: Laboratory data: Geophysics, 67, $1423-1440$.

Wenk, H.-R., Lonardelli, I., Franz, H., Nihei, K., and Nakagawa, S., 2007, Preferred orientation and elastic anisotropy of illite-rich shale: Geophysics: 72, E69-E75. 


\section{TABLES}

Table 1. Elastic properties of Phenolite

\begin{tabular}{|l|c|c|c|c|c|c|c|}
\hline \multicolumn{1}{|c|}{ sample } & $\begin{array}{c}\text { density } \\
\mathbf{( k g / \mathbf { m } ^ { 3 }}\end{array}$ & $\begin{array}{c}\mathbf{c}_{\mathbf{1 1}} \\
\mathbf{( G P a )}\end{array}$ & $\begin{array}{c}\mathbf{c}_{\mathbf{3 3}} \\
\mathbf{( G P a )}\end{array}$ & $\begin{array}{c}\mathbf{c}_{55} \\
\mathbf{( G P a )}\end{array}$ & $\begin{array}{c}\mathbf{c}_{66} \\
\mathbf{( G P a )}\end{array}$ & $\begin{array}{c}\mathbf{c}_{\mathbf{1 3}} \\
\mathbf{( G P a )}\end{array}$ \\
\hline \multicolumn{2}{|l}{ This study (phased array) } & 1357 & 16.87 & 10.54 & 2.75 & 3.40 & 6.65 \\
\hline $\begin{array}{l}\text { Hexagon block } \\
\text { measurements }\end{array}$ & (I) & 1357 & 15.33 & 11.63 & 3.24 & 3.59 & 5.59 \\
\cline { 2 - 8 } & (II) & 1357 & 17.07 & 11.63 & 3.02 & 3.49 & 6.67 \\
\hline Cheadle et al. (1991) & 1364 & 17.44 & 11.67 & 3.52 & 3.77 & 6.66 \\
\hline Mah et al. (2003) & 1395 & 15.9 & 11.1 & 3.0 & 3.8 & 6.8 \\
\hline
\end{tabular}

${ }^{1)}$ Results in (I) and (II) are the TI elastic constants determined for the two perpendicular planes along the axes of symmetry of the orthotropic block. Measurements (I) are in the $x_{1}-x_{3}$ plane, and measurements (II) are in the $x_{2}-x_{3}$ plane. 
Table 2. Normalized errors for the velocities (estimated), elastic constants (computed), and Thomsen's parameters (computed) obtained from the uncertainty analysis of Appendix A.

\begin{tabular}{|c|c|}
\hline \multicolumn{2}{|c|}{ velocity errors } \\
\hline$\Delta \mathrm{Vp} / \mathrm{Vp}$ & $\Delta \mathrm{Vs} / \mathrm{Vs}$ \\
\hline \hline $2 \%$ & $4 \%$ \\
\hline
\end{tabular}

\begin{tabular}{|c|c|c|c|}
\hline \multicolumn{4}{|c|}{ elastic constant errors } \\
\hline$\Delta \mathrm{c}_{11} / \mathrm{c}_{11}$ & $\Delta \mathrm{c}_{33} / \mathrm{c}_{33}$ & $\Delta \mathrm{c}_{55} / \mathrm{c}_{55}$ & $\Delta \mathrm{c}_{66} / \mathrm{c}_{66}$ \\
\hline \hline $4 \%$ & $4 \%$ & $8 \%$ & $8 \%$ \\
\hline
\end{tabular}

\begin{tabular}{|c|c|c|}
\hline \multicolumn{3}{|c|}{ Thomsen's parameter errors } \\
\hline$\Delta \varepsilon / \varepsilon$ & $\Delta \gamma / \gamma$ & $\Delta \delta / \delta$ \\
\hline \hline $38 \%$ & $38 \%$ & $60 \% *$ \\
\hline
\end{tabular}

*The normalized error for $\delta$ was computed from Eq. (A-10) under the assumption that the normalized error in $c_{13}$ is the same as for $c_{33}$. 


\section{FIGURES}

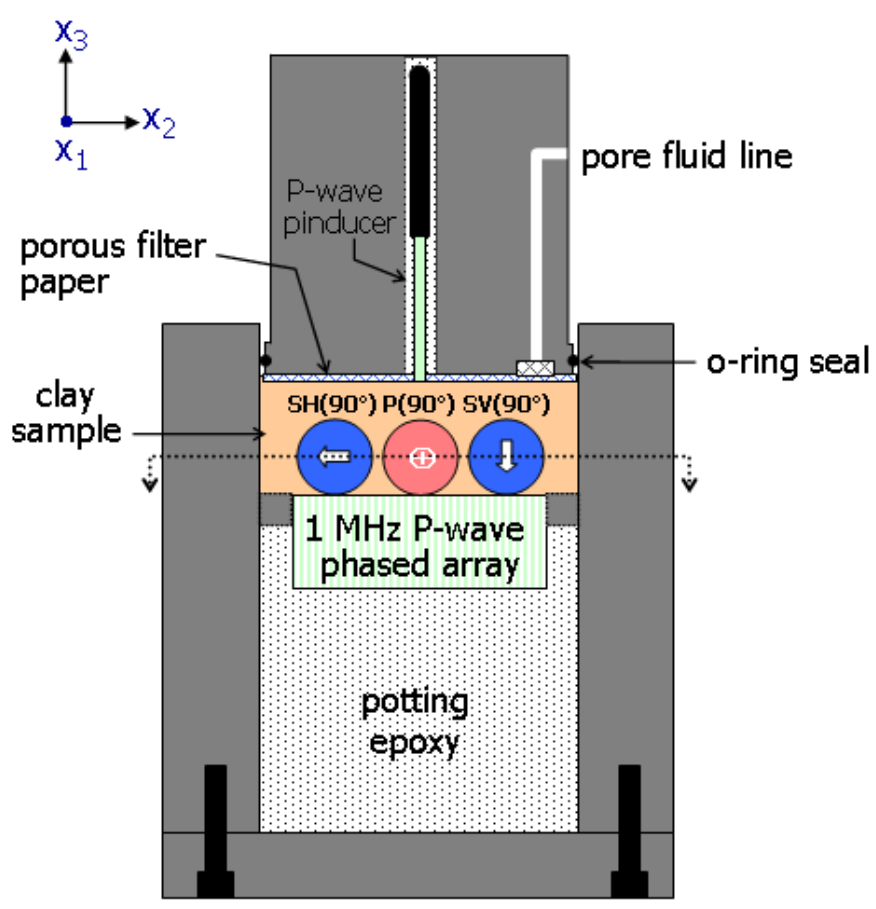

(a)

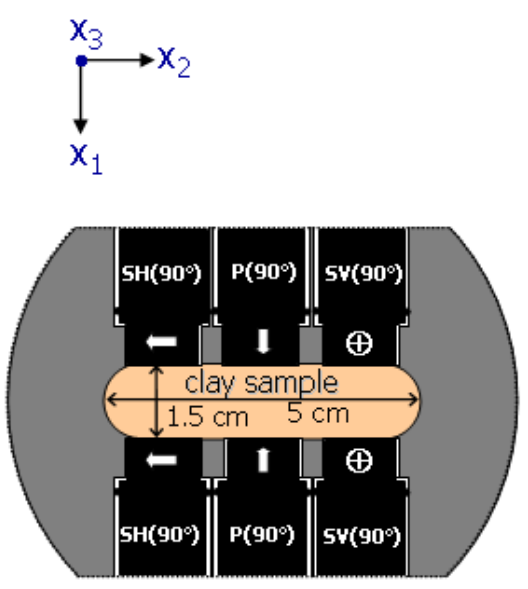

(b)

Figure 1. Schematic illustration of the phased array compaction cell for measuring the transverse isotropic elastic properties of soft sediments during uniaxial strain consolidation: (a) vertical cross-section through the cell showing the locations of the slot-shaped sample, the piezoceramic transducers, and the phased array, and (b) horizontal cross-section through the sample along the dotted line in (a). 


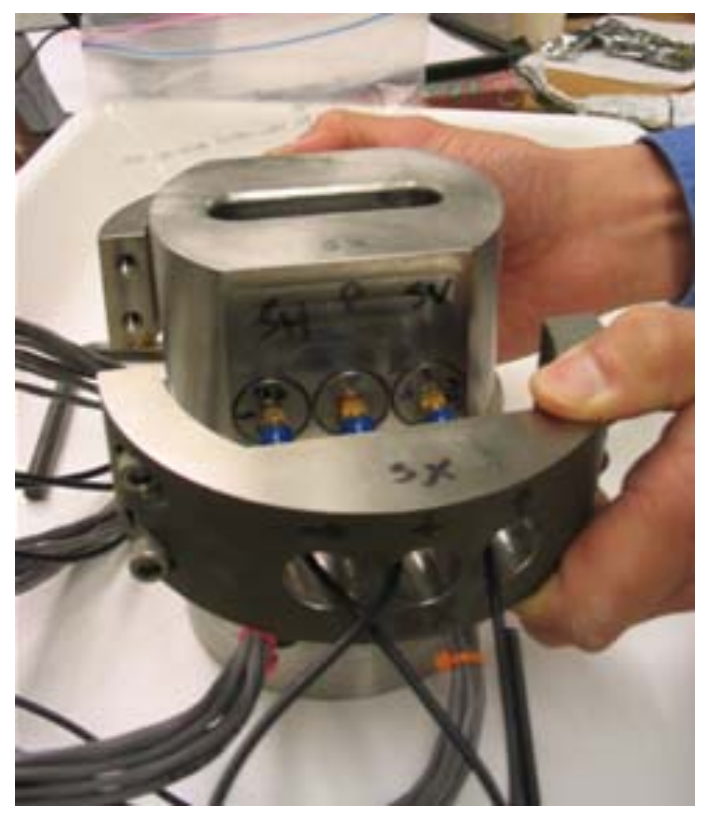

(a)

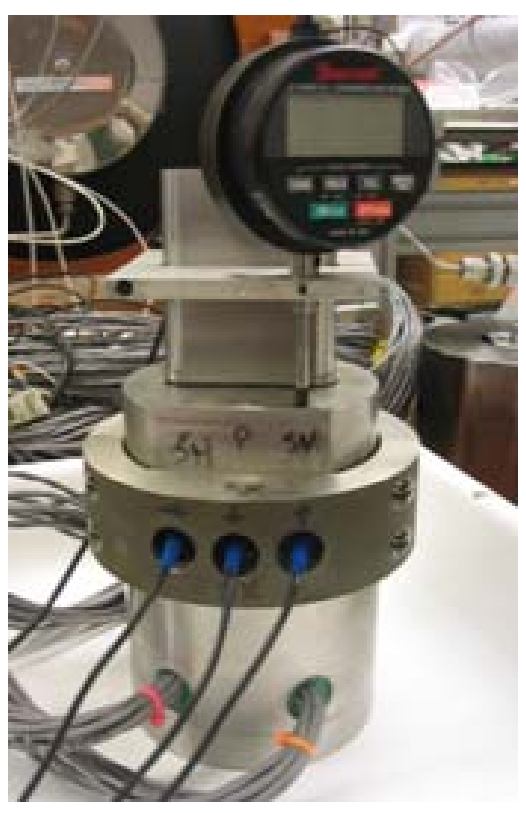

(b)

Figure 2. Photograph of the phased array compaction cell: (a) during assembly of the transducer clamp, and (b) fully-assembled with loading piston in-place and displacement transducer installed. 

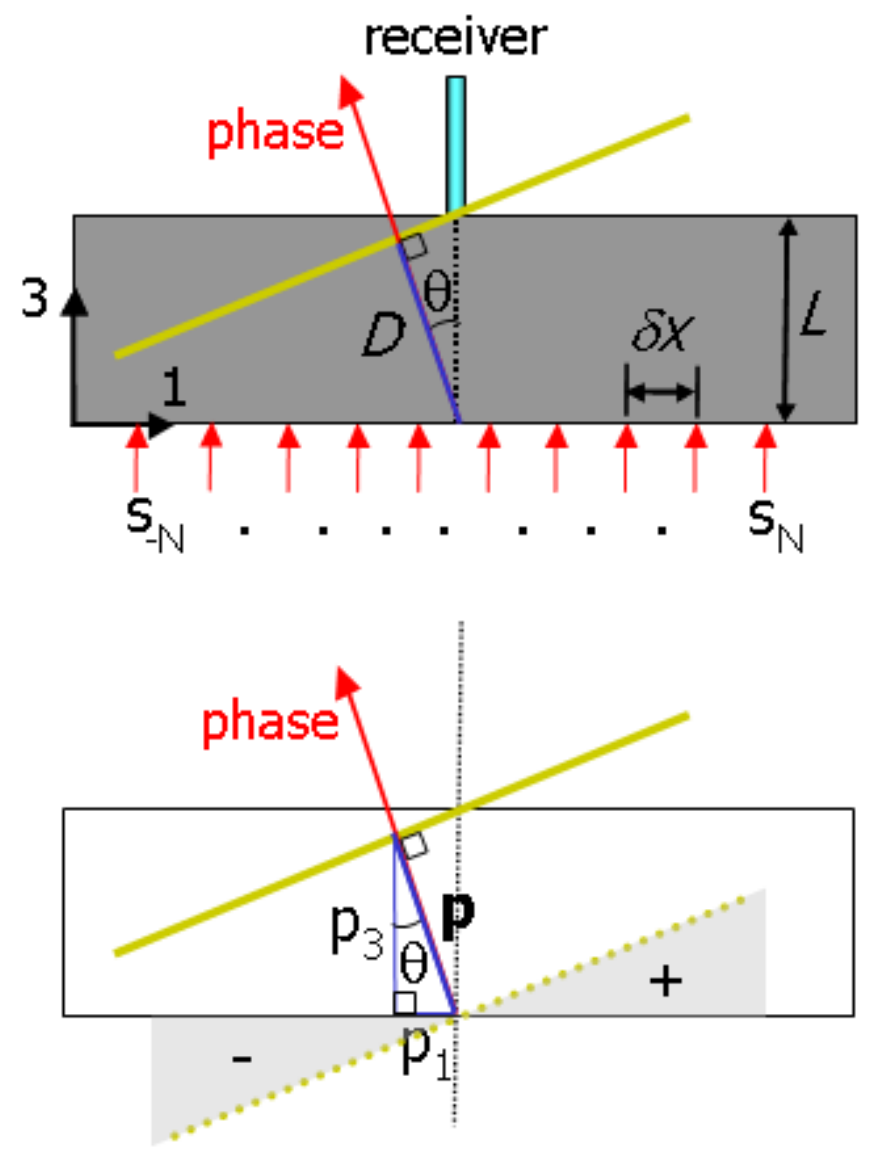

Figure 3. Synthesis of plane waves with a $2 \mathrm{~N}$ element phased array. The top figure shows the physical geometry: $L$ is the sample thickness, $\delta x$ is the source element spacing, and $D$ is the propagation distance of a plane wave with angle of incidence $\theta$. The lower figure shows the decomposition of the slowness vector $\boldsymbol{p}$ into horizontal and vertical components. The shading along the source locations illustrates the negative and positive time shifts applied to the common receiver data to synthesize the plane wave using Eq. (5). 


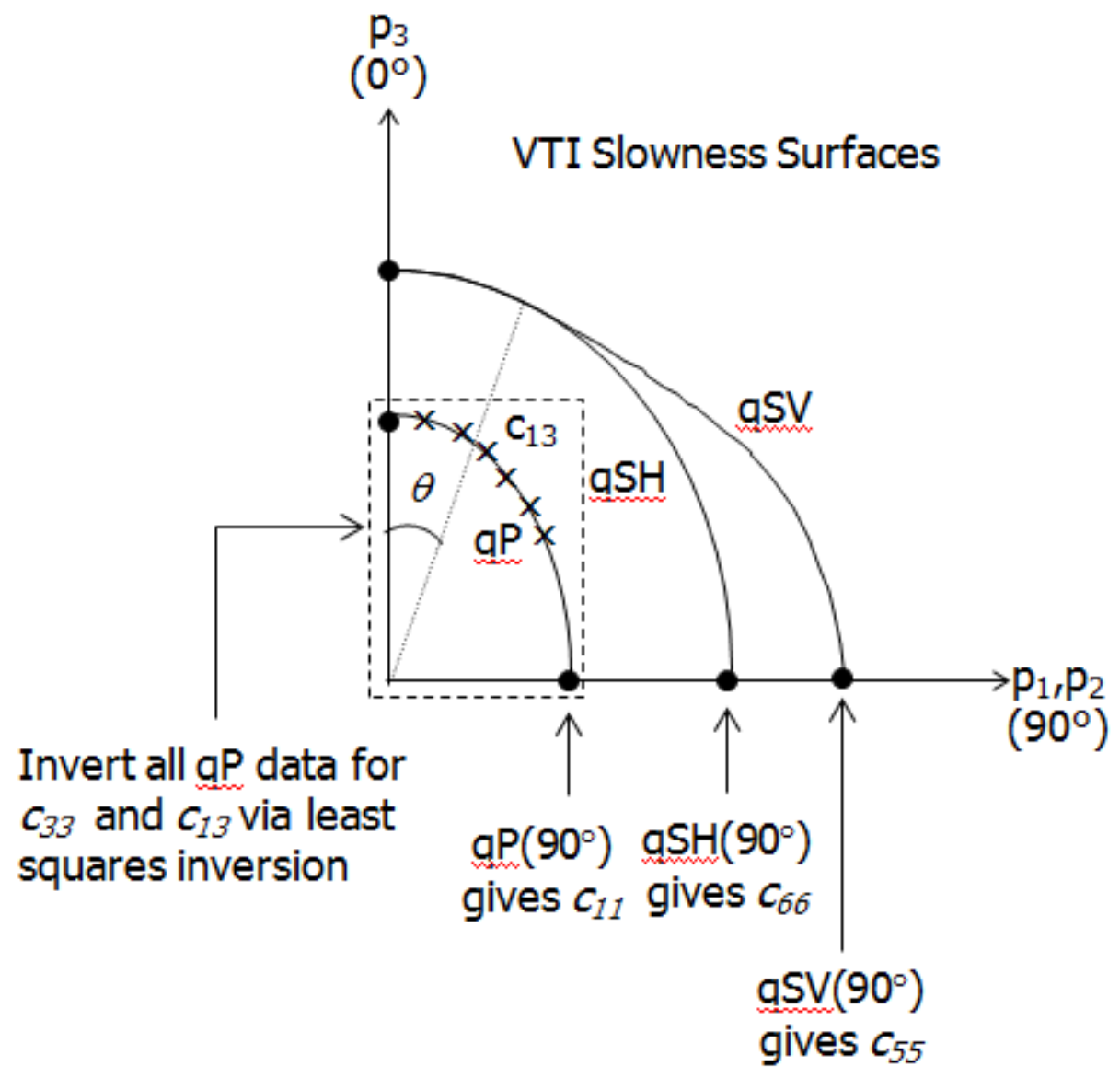

Figure 4. Slowness surfaces for a VTI material indicating the compressional and shear slowness measurements used to recover the 5 elastic constants. The closed circles are slownesses obtained from measurements along the axis and plane of symmetry. The crosses on the qP surface are slownesses obtained from synthetic phasing of the 32 element array measurements. 


\section{P-wave Phased Array Measurements}

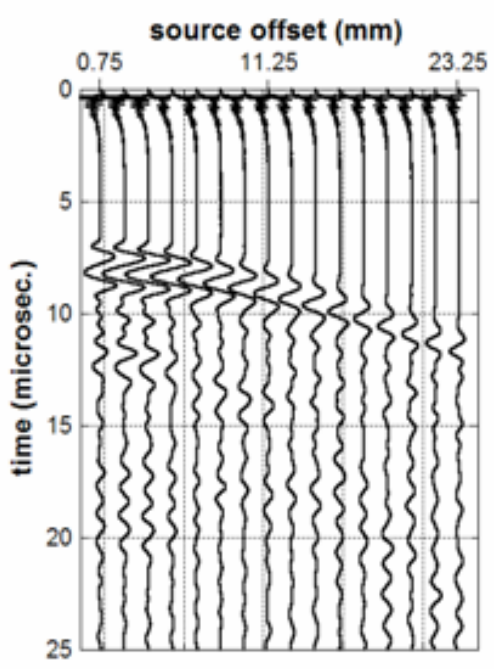

(a)

\section{Synthesized Plane Waves}

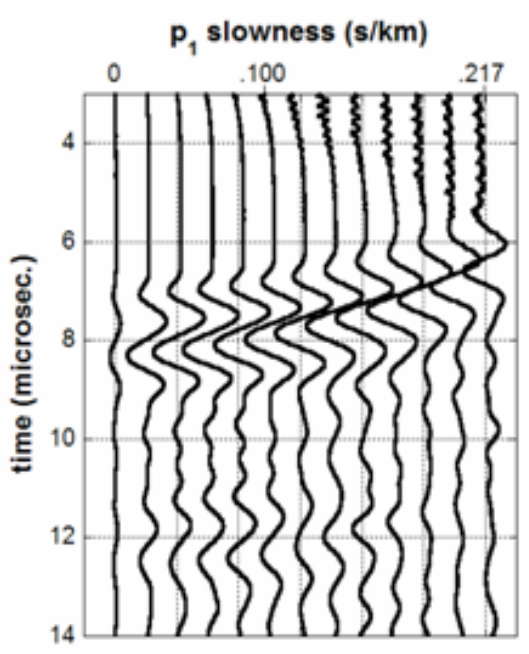

(b)

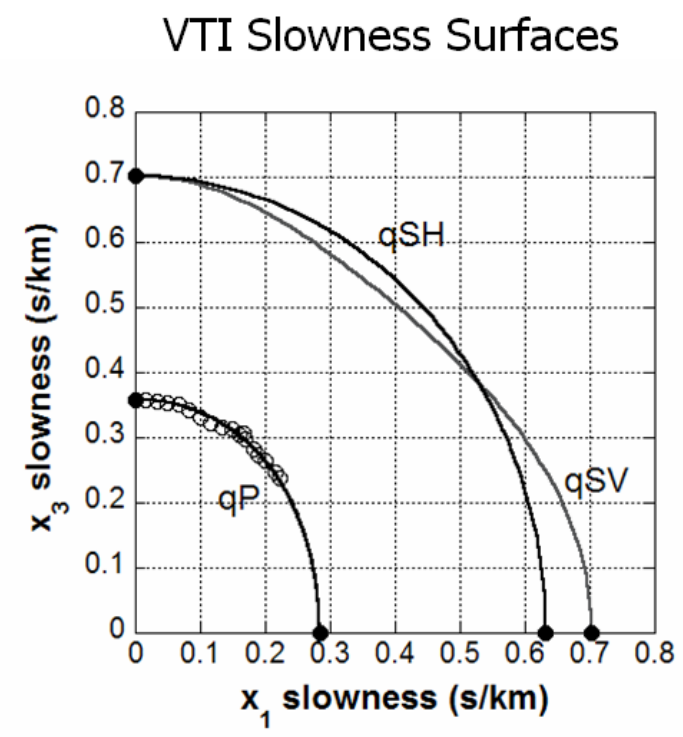

(c)

Figure. 5. Results for the Phenolite sample. (a) Common-receiver gather for 16 of the 32 elements of the phased array compressional wave source. (b) Common-receiver gather of (a) after transformation from time-offset to time-slowness (tau-p). (c) Recovered VTI slownesses that were obtained assuming the two horizontal slownesses are identical (i.e., $p_{1}=p_{2}$ ). The open circles correspond to qP phase slowness measurements obtained by synthetic phasing of the 16 element array measurements. 

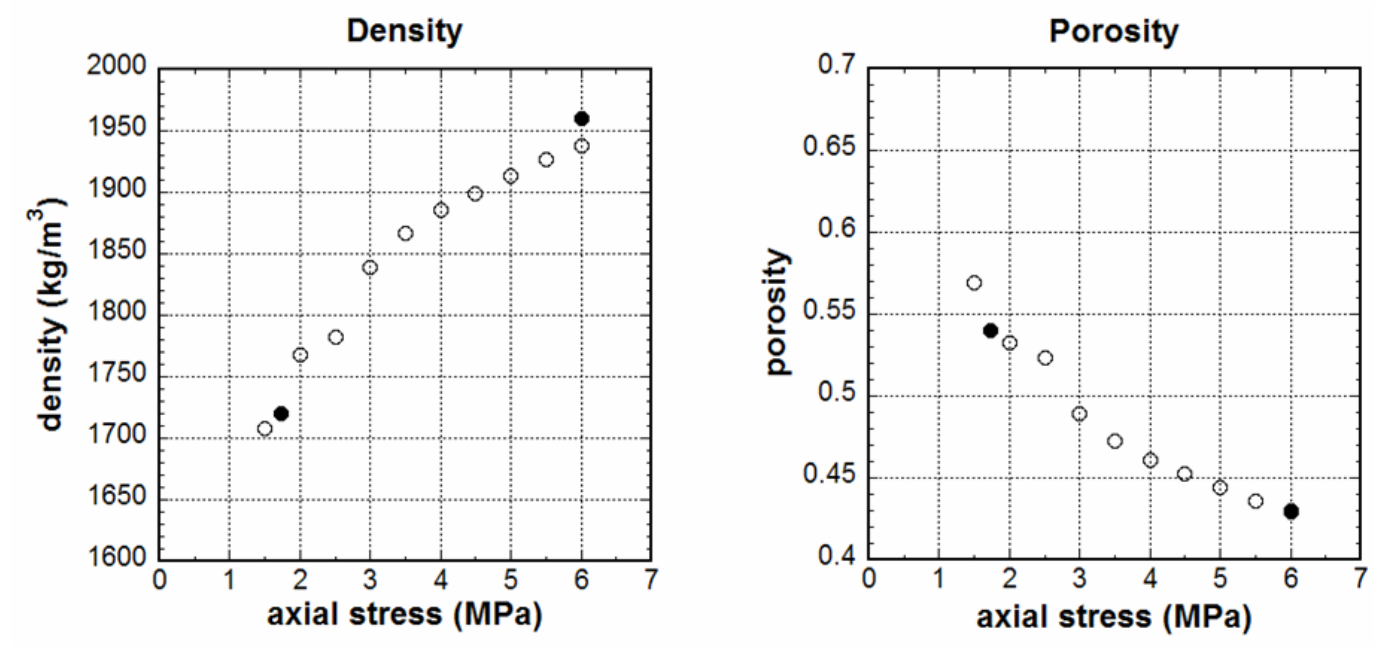

Figure 6. Density (left) and porosity (right) measured on a Gulf of Mexico clay-rich sediment sample subjected to uniaxial strain loading conditions. The sample was taken from $76.4 \mathrm{~m}$ below mud line and contains $65 \%$ clay. Data points with filled circles denote density and porosity measurements made on the sample prior to compaction (1.73 MPa is estimated in situ axial stress) and post-compaction (5.97 MPa). Open circles denote density and porosity values inferred from the measured length change and expelled pore fluid during the compaction of the sample. 

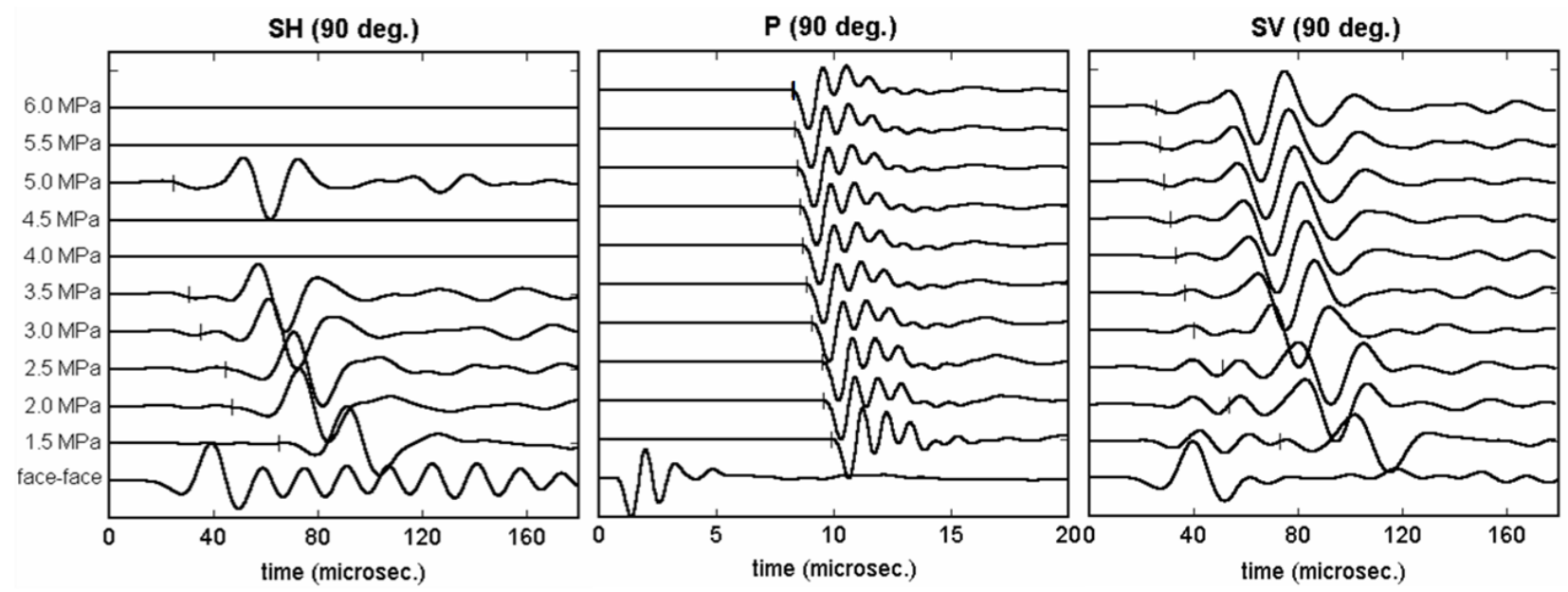

Figure 7. SH, P, and SV traces for transmission along the $x_{1}$ direction (Fig. $1 \mathrm{~b}$ ) recorded during compaction of the clay-rich sample. The lower-most traces are reference waveforms obtained by placing the source and receiver transducers face-to-face. The vertical bars denote travel time picks obtained by cross-correlation with the face-to-face reference trace. The SH traces for 4.0, 4.5, 5.5 and 6.0 MPa do not show recorded waves because of an intermittent short in the $\mathrm{SH}$-wave transducer. 


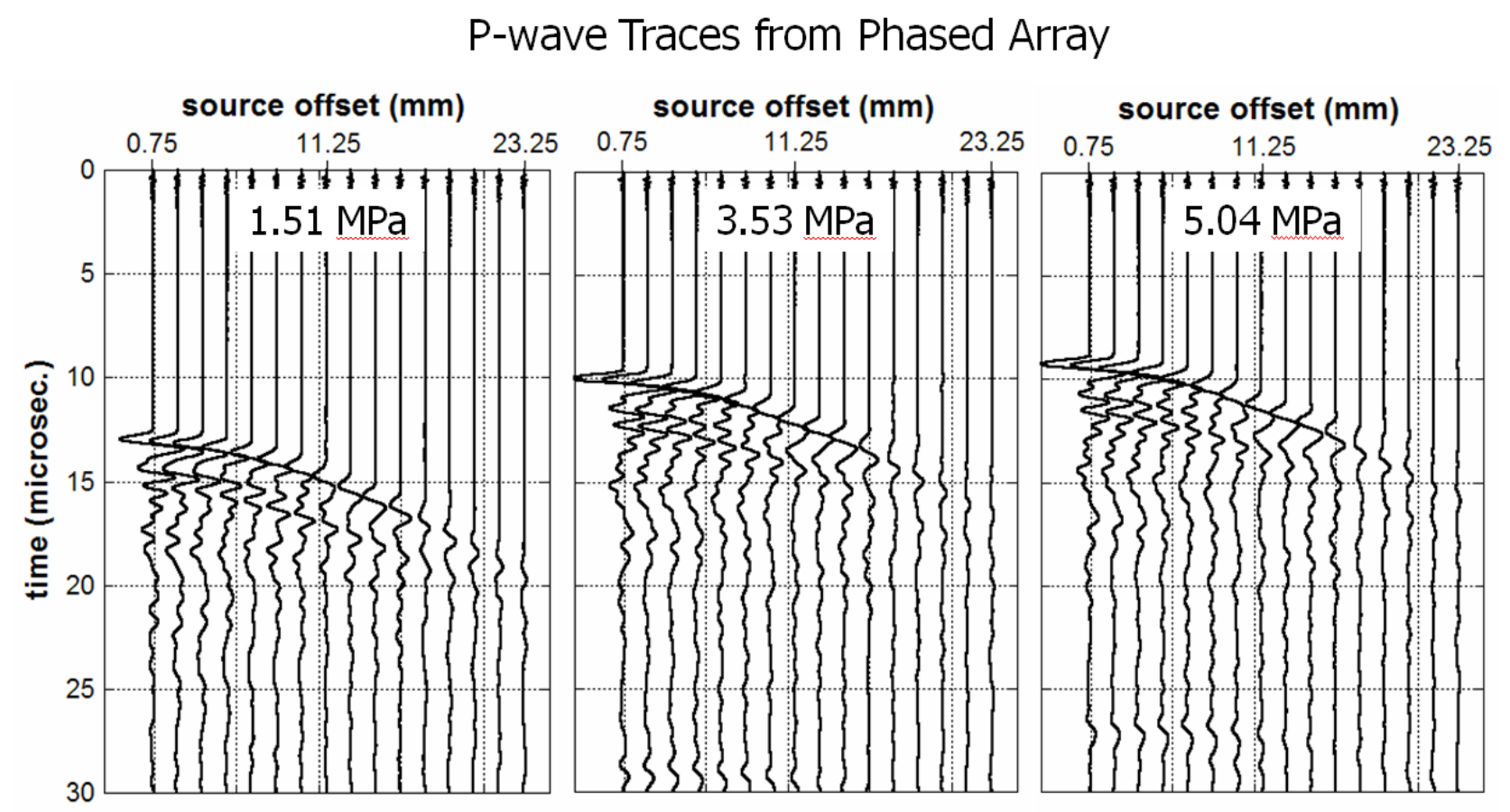

Figure 8. qP common-receiver gathers for three axial stresses during compaction of the clay-rich sediment displaying traces for 16 elements of the phased array source. qP propagation is in the $x_{2}-x_{3}$ plane, as depicted in Fig. 1a. 


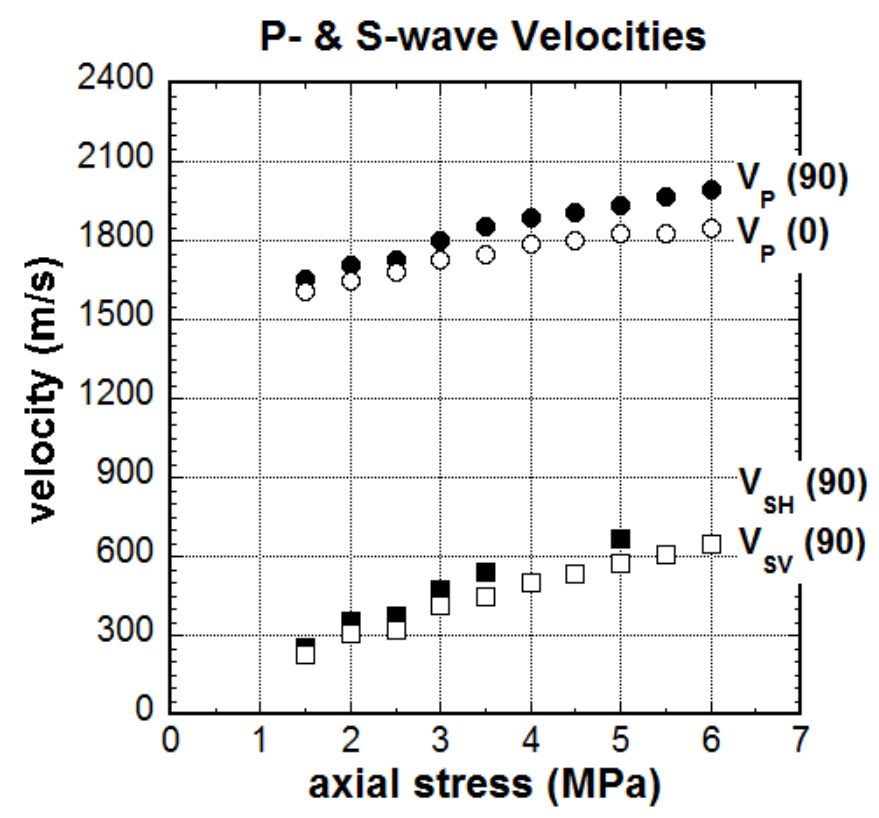

Figure 9. P- and S-wave velocities during compaction of the clay-rich sediment obtained from travel time measurements along the $x_{1}$ direction (Fig. 1b). The $\mathrm{V}_{\mathrm{P}}(0)$ velocity was obtained from measurements along the $x_{3}$ direction using the phased array (Fig. 1a). Velocity error estimates are given in Table 2. 


\section{Slowness Surfaces}
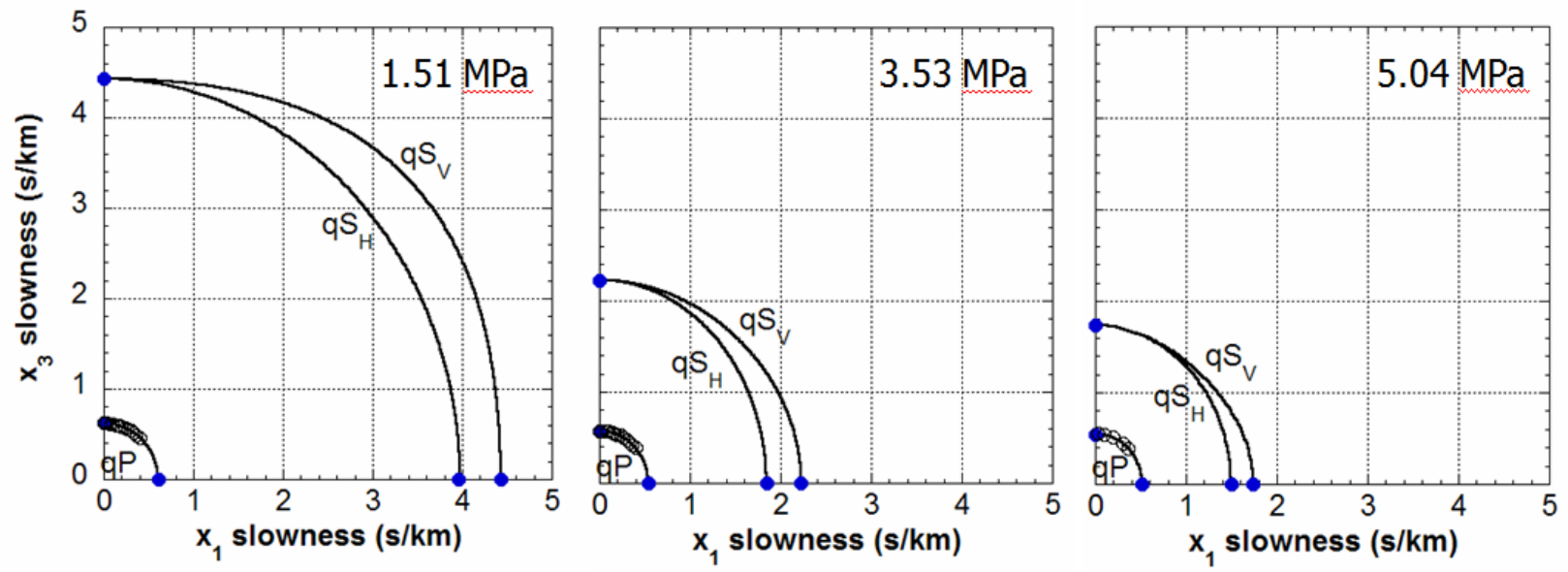

Figure 10. Evolution of the slowness surfaces for the clay-rich sediment during compaction. The two horizontal slownesses are assumed identical (i.e., $p_{1}=p_{2}$ ) in accordance with VTI anisotropy. 

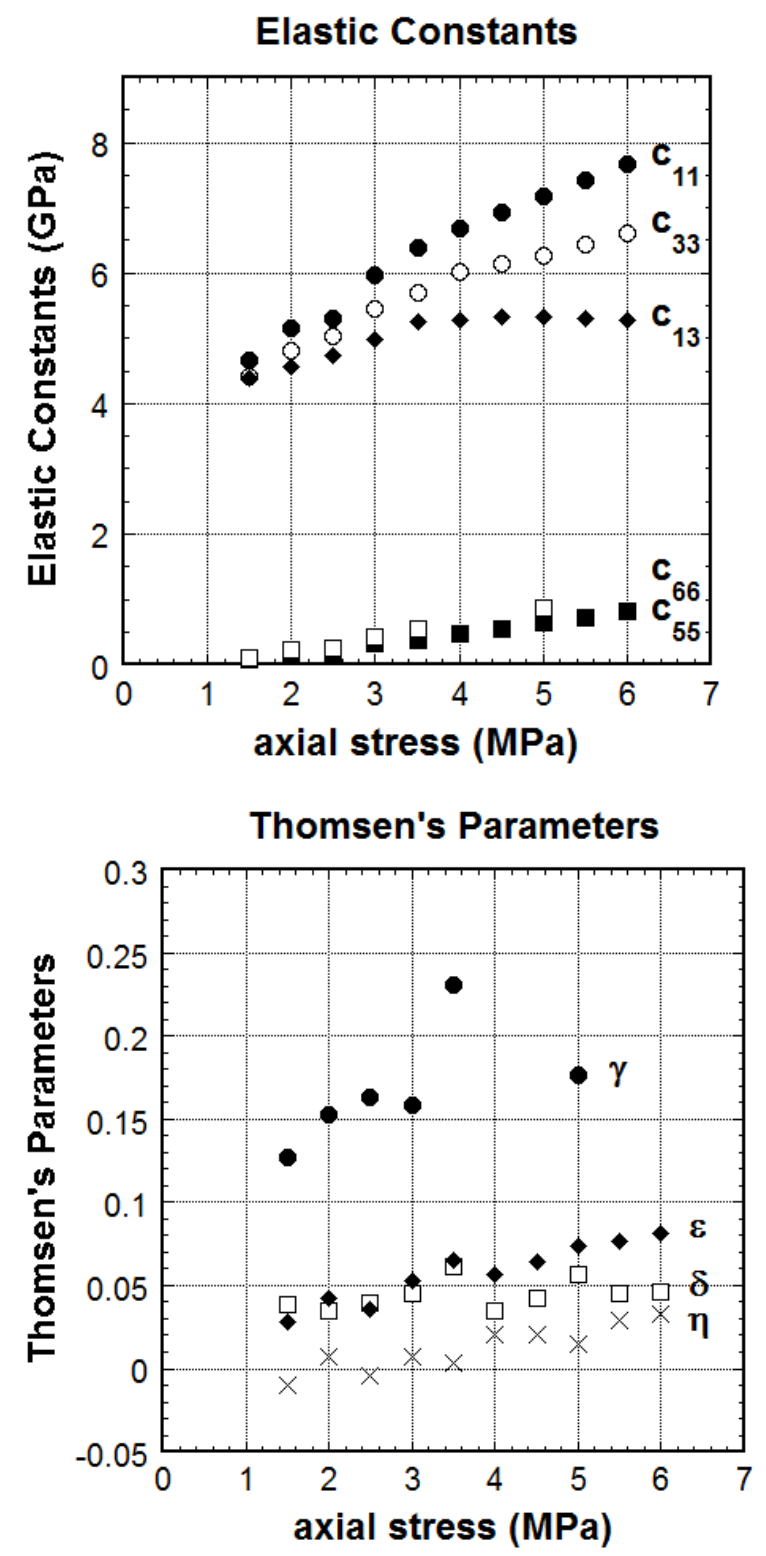

Figure 11. Elastic constants (left) and Thomsen's parameters (right) as a function of compaction for the clay-rich sediment. Error estimates are given in Table 2. 
SEM
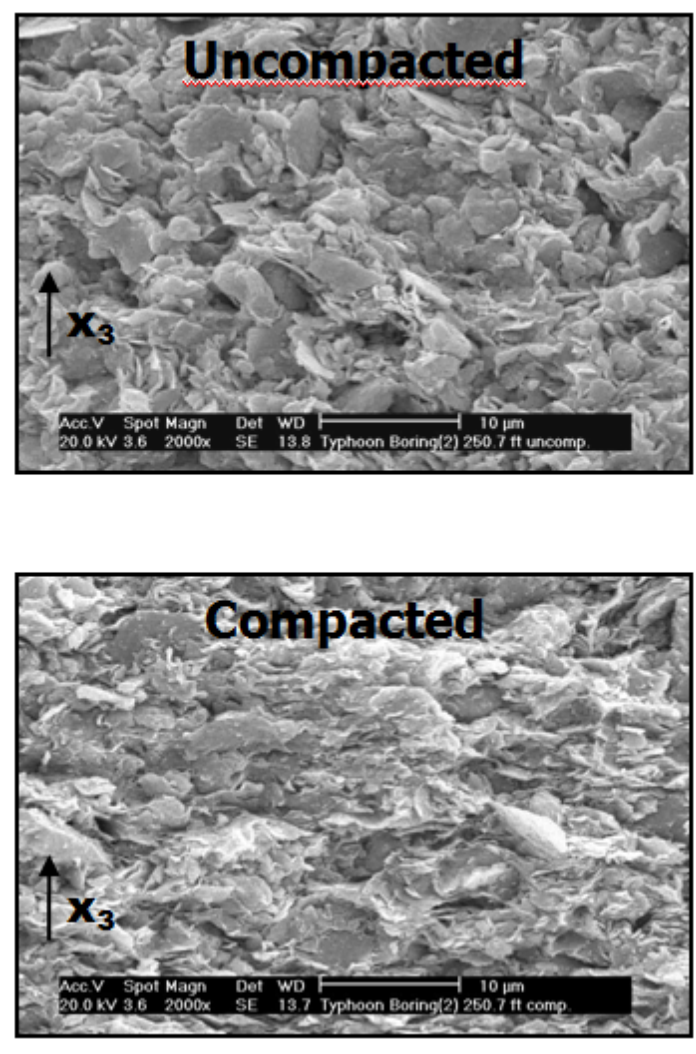

EDAX (Elemental Analysis)
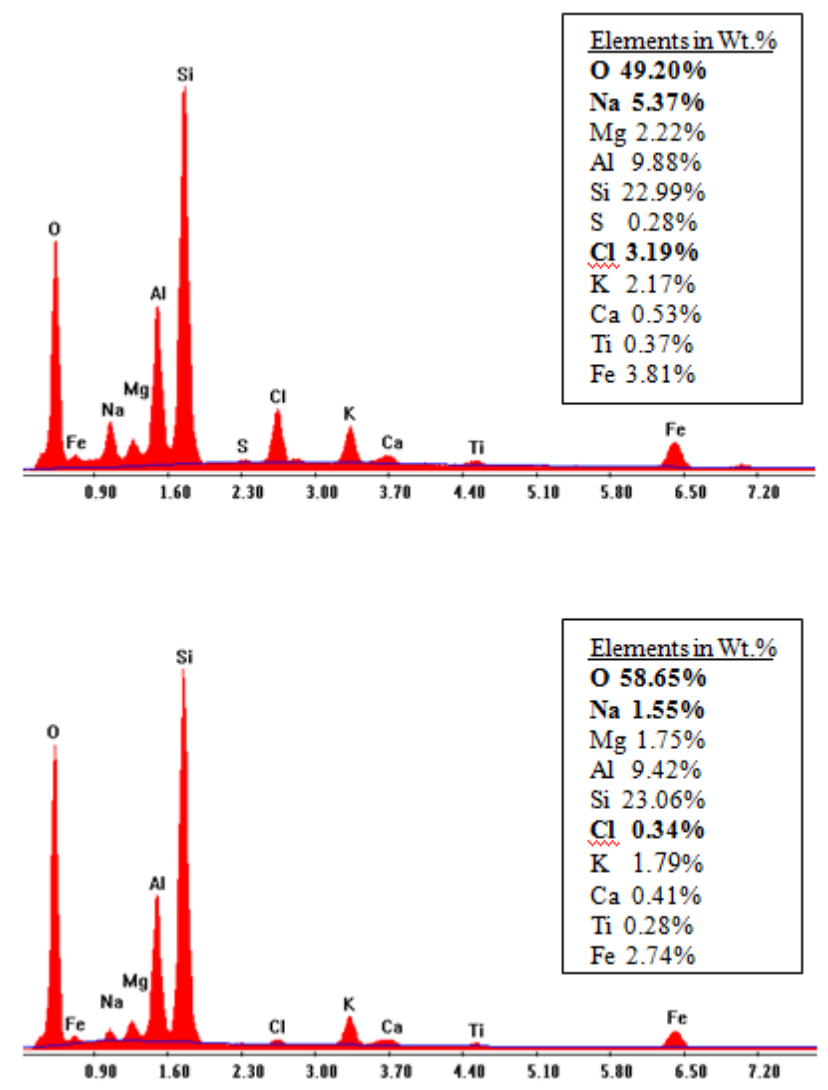

Figure 12. Pre- and post-compaction scanning electron microscope (SEM) images taken along vertical slices through the sample (left), and energy-dispersive X-ray spectroscopy (EDAX) elemental composition (right) of the clay-rich sediment. The reduction of porosity from $57 \%$ to $43 \%$ is reflected in the change in texture and the loss of pore fluid as the sample is compacted. 
Kaolinite-Chlorite Pole Figure (contour interval $=0.11$ )

max. pole density $=1.76$

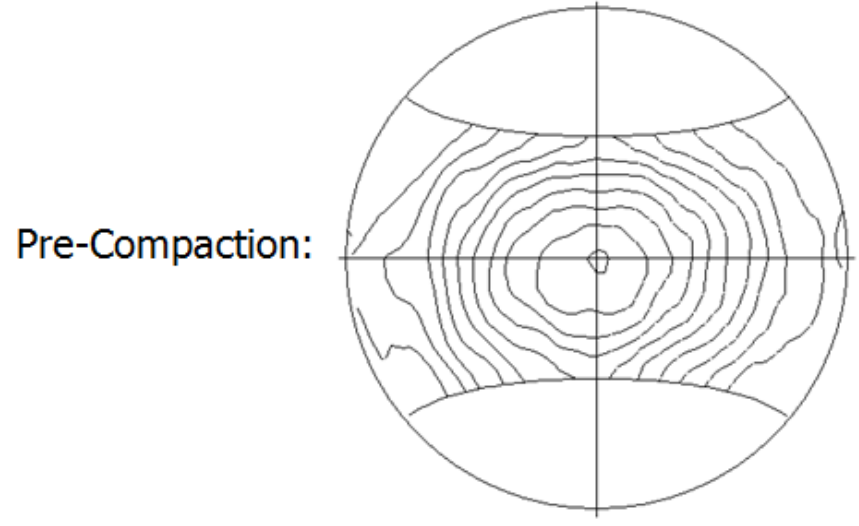

max. pole density $=2.17$

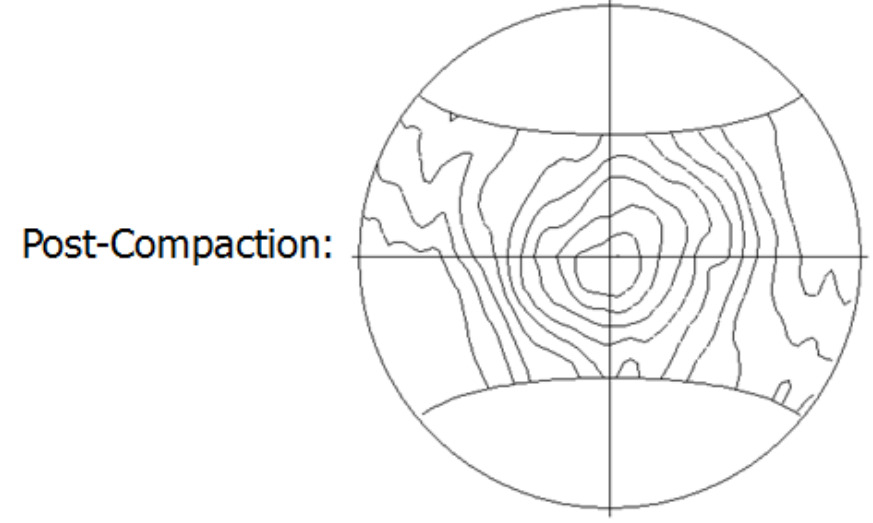

Illite-Smectite Pole Figure

(contour interval $=0.11$ )

max. pole density $=1.89$

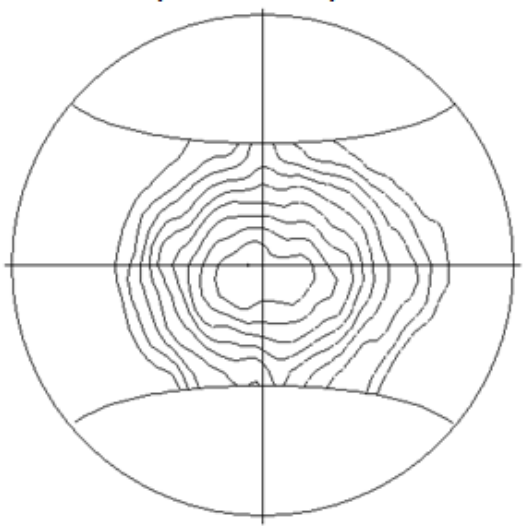

max. pole density $=2.33$

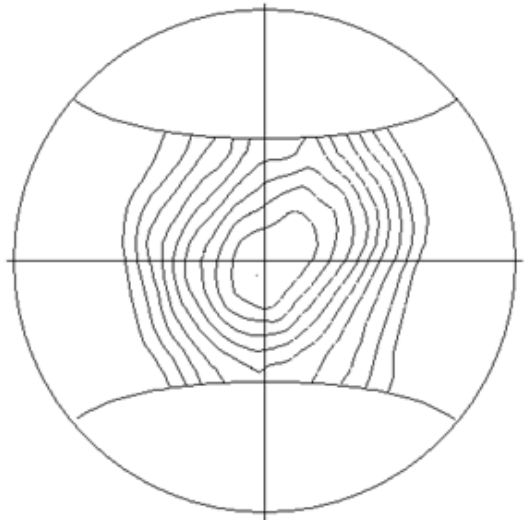

Figure 13. Pre- and post-compaction X-ray goniometry pole figures in units of multiples of a random distribution [m.r.d.] show an increase in the alignment of the clay platelets resulting from compaction of the clay-rich sediment. 


\section{DISCLAIMER}

This document was prepared as an account of work sponsored by the United States Government. While this document is believed to contain correct information, neither the United States Government nor any agency thereof, nor the Regents of the University of California, nor any of their employees, makes any warranty, express or implied, or assumes any legal responsibility for the accuracy, completeness, or usefulness of any information, apparatus, product, or process disclosed, or represents that its use would not infringe privately owned rights. Reference herein to any specific commercial product, process, or service by its trade name, trademark, manufacturer, or otherwise, does not necessarily constitute or imply its endorsement, recommendation, or favoring by the United States Government or any agency thereof, or the Regents of the University of California. The views and opinions of authors expressed herein do not necessarily state or reflect those of the United States Government or any agency thereof or the Regents of the University of California. 